\title{
From the Editor
}

\section{This is the first issue of the Review of Middle East Studies.}

Continuing the long and distinguished run of the Middle East Studies Association Bulletin, the Review is MESA's home for metascholarship: reviews of the state of the field and the craft of Middle East studies, and reflections on its past, its purpose, and its future directions.

This issue begins with two retrospectives. The first is a special section on the thirtieth anniversary of Edward Said's Orientalism, which includes both Mervat Hatem's Presidential Address, and three of the four papers from the Presidential Plenary Session from the 2008 MESA meetings ("Celebrating the Thirtieth Anniversary of Orientalism: Critiques and New Insights"). While some critics have portrayed MESA's membership uniformly as "Said's slavish acolytes, mindlessly praising and repeating the master's every word," as former President Zachary Lockman recalls (MESA Bulletin 42 (1\&2), 2008, p.10), these contributions point instead in different directions. Hatem comments on the mixed reception Orientalism's critique received within the field here and in the Middle East; François Burgat highlights Said's counterproductive silence on some of the most consequential political developments in the region; Ella Shohat analyzes the book's implications within multiple fields of regional, 
subaltern, feminist, and cultural studies; and Denise Spellberg describes the vital role that semiotically complex Orientalist stereotypes played in some of the most foundational debates in American political history.

The second retrospective is the first in an occasional series of personal reflections on their early work by distinguished scholars in the field, this by Professor Roger Owen, A. J. Meyer Professor of Middle East History at Harvard University. The essay will be of interest to intellectual historians as well as to graduate students who are embarking on their own scholarly careers. I want to thank Magnus Bernhardsson and Najwa al-Qattan for the idea and the arrangements. The Review welcomes other members of the leading generation of Middle East scholars to contribute their own research retrospectives to future issues.

In our next issue, we will feature another special section, on the uses of culture in the contemporary Middle East. We will also publish the first in our regular series of literature reviews-on Jewish settlers in the Occupied Territories-as well as a full complement of book reviews. Please join us also in welcoming Erik S. Ohlander of Indiana University-Purdue University Fort Wayne, as our new Associate Editor for Religion.

\section{A note on the redesign}

The journal is set in Gentium Book Basic, an open-source typeface designed by Victor Gaultney at the University of Reading (U.K.) in 2003. We have chosen it for its readability, its aesthetic quality, which is inspired by pen-and-ink calligraphy, and for its broad support of the extended Latin characters used in transliterating Middle Eastern languages. The inside layout and cover have been designed by Ikarus Design.

Gregory Starrett Editor 